\title{
The Development and Design of an All-Digital EMA AC Servo System
}

\section{ZHU Xiao-Rong ${ }^{1, \text { a }}$, ZHENG Ji-Gui ${ }^{1, b}$, GUO Ya-Jing ${ }^{1, c}$, ZHANG He ${ }^{1, \mathrm{~d}}$ and ZHENG Hua-Yi ${ }^{1, e}$}

\author{
${ }^{1}$ Beijing Research Institute of Precise Mechatronics and Controls, China \\ a zxrtju@163.com, bzhengjigui@163.com, ${ }^{c}$ gyj_buaa@163.com, ${ }^{\mathrm{d}}$ zh710@aliyun.com, \\ ehuayizheng@163.com
}

Keywords: Actuator, AC servo system, Vector control

Abstract. The actuator servo system is an essential part of the missile system, whose characteristics directly affect the missile's performance. An all-digital electromechanical actuator (EMA) system is designed based on field-oriented vector control principle, and its prototype is developed, which has fast transient response, high static accuracy and small torque ripple, runs smoothly at low speed and are particularly applicable to high performance speed control cases as in an actuator system.

\section{Introduction}

Guided weapons 'development must meet the new requirements of modern war, missiles are undoubtedly the best at long-range strike guided weapons, and the missile actuator system's performance directly determines the dynamic quality of the missile fight $[1,2]$. Compared with pneumatic and hydraulic actuator system, EMA system has advantages like small volume, light quality, small time constant, good load characteristics, high reliability, easy to implement redundancy control, which is gradually meeting the missile's requirements. Therefore EMA system is used more and more widely in missiles, combined guidance ammunition and other advanced aircrafts, and has become one of the important studies in many countries' air force research [3, 4, 5].

The AC servo motor system is designed according to the field-oriented vector control principle, which has fast transient response, high static accuracy, small torque ripple and comparatively large speed regulation range, runs smoothly at low speed, and is particularly applicable to high performance speed control case as in actuator system [6,7]. All-digital actuator AC servo system is of great significance to national defense, so one is designed and its prototype is developed in this study.

\section{The overall scheme design of the servo motor}

\section{The summary of the overall scheme design}

The actuator servo system is an essential part of the missile system, whose characteristics directly affects the missile's performance. Its main function is to control the surface, which requires rapidly and accurately deflecting to ensure the static and dynamic indexes of the actuator control. The actuator servo system is essentially a typical position servo system, whose working principle is shown in Fig.1.

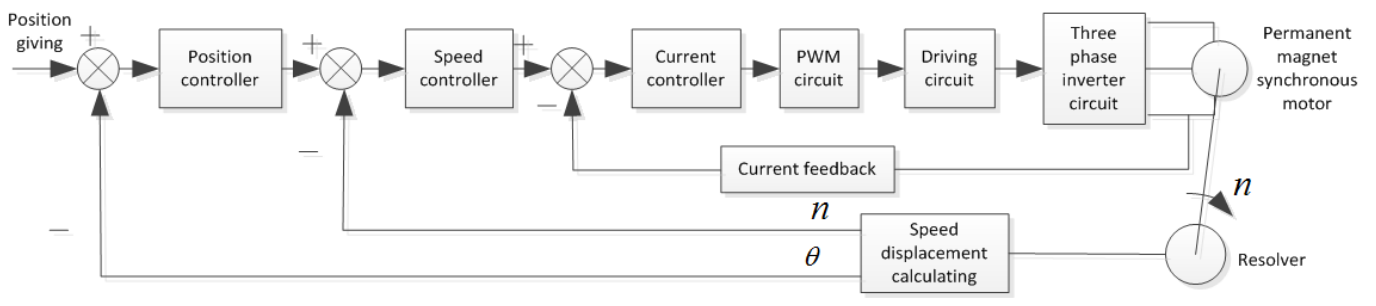

Fig. 1 the principle diagram of the EMA AC servo system

In general servo motor the rated speed is high and the rated torque is small, while, in this study the ball screw is used in the AC servo system, which can meet the requirements of reduction ratio and structure layout. In the eletromagnetic scheme, the high performance rare-earth $\mathrm{NdFeB} 35 \mathrm{SH}$ is used to improve the working air gap magnetic flux density and make the motor's mechanical properties 
harden. The typical sine wave AC permanent magnet structure is used: the stator is symmetrical three-phase windings, the rotor is the multipolar system composed of high performance rare-earth, whose surface is covered with permanent magnet.

\section{Design parameters}

In this all-digital electromechanical actuator ac servo system, the sine wave current vector control is used, whose main technical indicators, size and electromagnetic parameters are shown in Table 1.

Table1 the design parameters of the all-digital EMA servo system

\begin{tabular}{cccc}
\hline parameter & value & parameter & value \\
\hline Phase number & 3 & Permanent magnet axial length $[\mathrm{mm}]$ & 20 \\
Pole pairs & 4 & Armature outer diameter[mm] & 150 \\
Rated power[kW] & 1.744 & Armature inter diameter[mm] & 100 \\
Rated current[A] & 55 & No-load torque[Nm] & 0.299 \\
Rated voltage[V] & 96 & Output torque[Nm] & 3.7 \\
Rated speed[r/min] & 4500 & Rated working electromagnetic & 3.999 \\
Rated torque[N m] & 3.7 & torque[Nm] & 4.0 \\
Efficiency & $85 \%$ & Motor weigh[kg] & 1 \\
Polar distance[mm] & 39.27 & Controller weigh[kg] & $170 \times 67$ \\
Air gap[mm] & 0.5 & Controller size $[\mathrm{mm} \times \mathrm{mm} \times$ mm] & $125 \times 100 \times 80$ \\
\hline
\end{tabular}

\section{Development of the prototype}

\section{Finite element analysis of the prototype}

To develop the all-digital EMA AC servo system's prototype, a two-dimensional finite element analysis with Ansoft's FEM software is done to verify whether the theoretical analysis meet the technical requirements. First, calculate no-load magnetic flux density, adjust the motor size to make its magnetic flux density of air gap, tooth and yoke to meet the design's requirements. Second, check no-load back EMF, whose waveform should be fine sinusoidal. Last, calculate the motor load torque output and the motor torque ripple, whose relation curve is calculated in id=0 control mode.

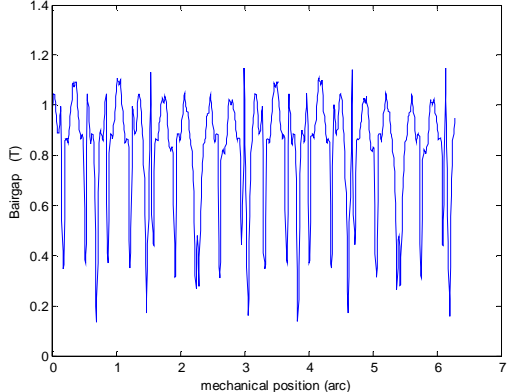

a)No-load air gap magnetic flux density

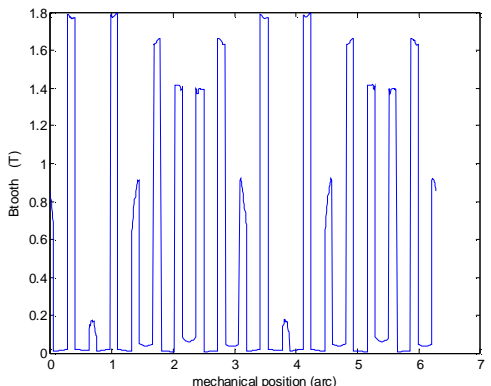

b)No-load tooth magnetic flux density

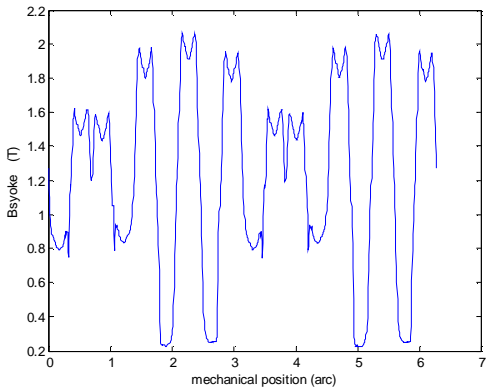

c) No-load stator yoke magnetic flux

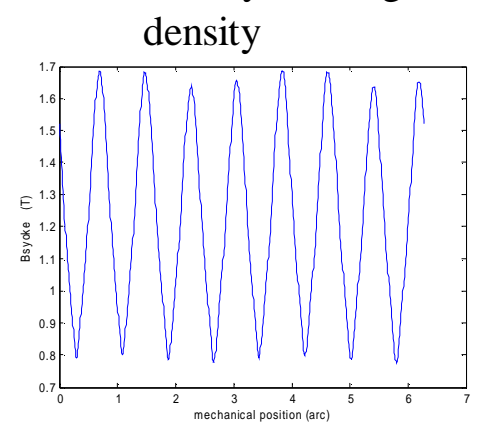

d) Rotor yoke magnetic flux density

Fig.2 no-load motor magnetic flux density 


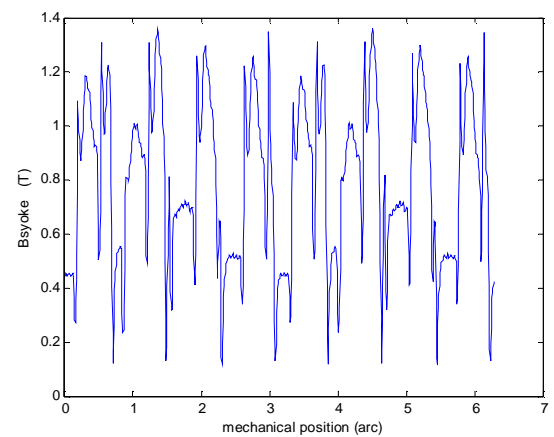

a)Load air-gap magnetic flux density

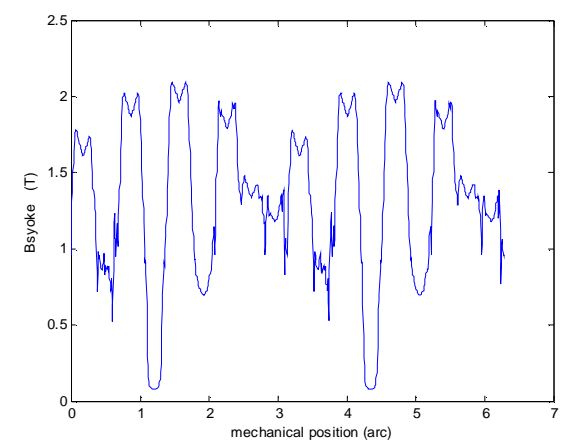

c)Load stator yoke magnetic flux density (80A)

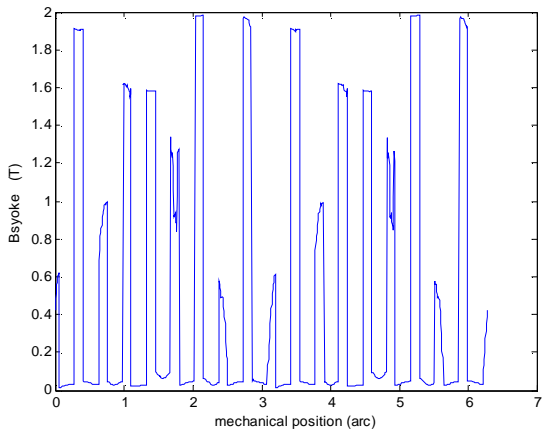

b)Tooth magnetic flux density (80A)

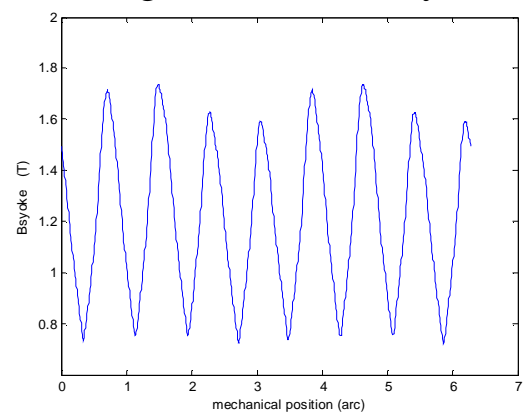

d) Rotor yoke magnetic flux density (80A)

Fig.3 load motor magnetic flux density

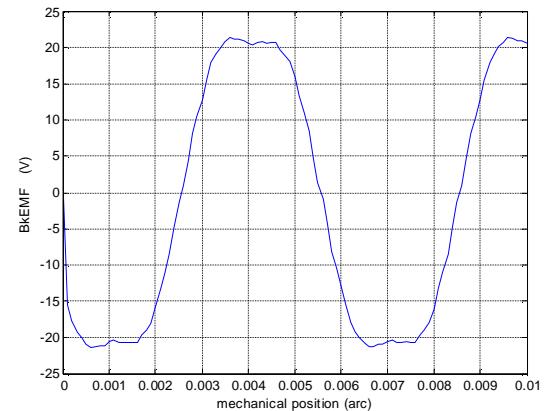

Fig.4 no-load back EMF waveform

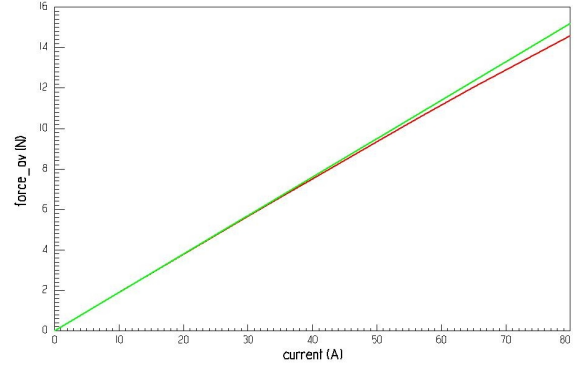

Fig.5 relation curve of the motor torque and current

As is shown in Fig.2 and Fig.3, average motor air gap magnetic flux density reaches 0.9 T, average tooth magnetic flux density $1.3 \mathrm{~T}$ with the toppest $1.8 \mathrm{~T}$, average rotor yoke magnetic flux density 1.25T. From the perspective of design the motor tooth and yoke has been effectively utilized, and at the maximum current input all the parts are under the saturation point of the silicon-steel sheet, which can ensure the motor work effectively and the magnetic steel not demagnetize. Fig. 4 illustrates that back EMF contains some higher harmonic whose amplitude is very small. Fig.5 shows that torque and current are basically in linear relationship, and at the maximum current the motor output decreases little. The back EMF's sine degree and the motor's around 4\% torque ripple meet the requirements of the servo system. The prototype's theoretical analysis meets the given technical requirements.

\section{Experiments and data analysis of the prototype}

The prototype is tested by experiments whose results is shown below.

(1) Motor phase winding back EMF (line voltage)

With a prime mover dragging the motor tested, the windings line voltage is tested, for the star connection is used in the windings without midline extraction. Fig. 6 shows the back EMF line voltage waveform when the motor speed is 3300rpm. The relationship between the motor line back EMF and the speed is shown in Table 2, the curve of which is shown in Fig.7. 
Table 2 The motor back EMF's change with speed

\begin{tabular}{c|c|c|c|c|c|c|c|c|c|c|c|c}
\hline speed (rpm) & 300 & 600 & 900 & 1200 & 1500 & 1800 & 2100 & 2400 & 2700 & 3000 & 3300 & 3600 \\
\hline Back EMF (V) & 1.4 & 6.9 & 10.5 & 14.0 & 17.6 & 21.1 & 24.6 & 28.1 & 31.5 & 35.1 & 38.6 & 42.1 \\
\hline
\end{tabular}

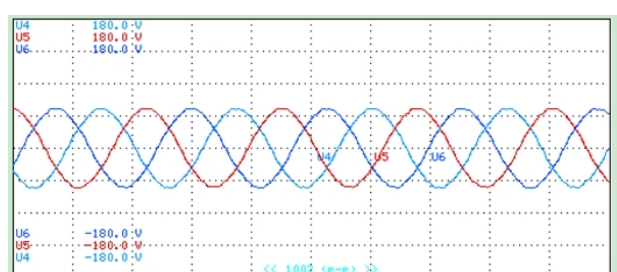

Fig.6 the back EMF line voltage waveform at the speed of $3300 \mathrm{rpm}$

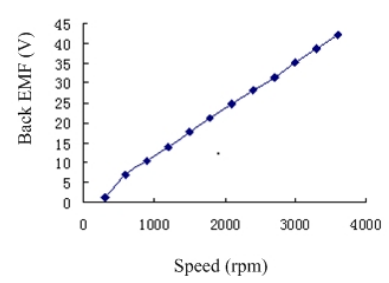

Fig. 7 the curve of the speed and back EMF

(2)Load experiments

The working characteristic curve of the motor system is shown in Fig.8. At 3300rpm motor constant torque is $9 \mathrm{Nm}$, and at 4500rpm motor maximum torque is $4.5 \mathrm{Nm}$.

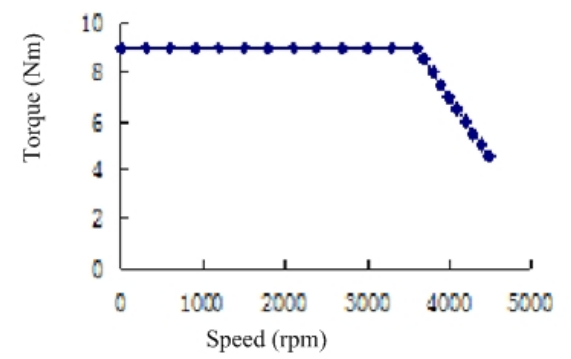

Fig. 8 the system's external enveloping curve

On the fixed speed, the relationship between current and motor output is shown as in Fig.9. DC bus' working voltage is $96 \mathrm{~V}$ with allowable fluctuation range $\pm 10 \%$. When DC bus voltage is $94.9 \mathrm{~V}$, load torque is $3.5 \mathrm{Nm}$ and speed is $4500 \mathrm{rpm}$, then motor current is $24.8 \mathrm{~A}$ more than rated current $17 \mathrm{~A}$, but much less than allowance peak current $50 \mathrm{~A}$.

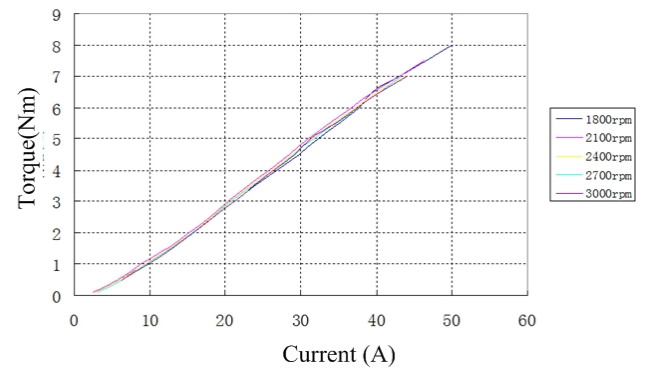

Fig. 9 the relationship curve of torque and current on fixed speed (3300 500rpm)

(3)The system frequency

An sine wave with adjustable frequency and amplitude voltage $0.235 \mathrm{~V}$ (the angle the motor shaft outputting is about $\pm 96^{\circ}$ )output by a signal generator works as motor position given signal; connecting the motor output shaft and the potentiometer rotation button works as position feedback signals. The signal frequency is increased gradually from $1 \mathrm{~Hz}$ with step size $1 \mathrm{~Hz}$, feedback signal waveform is observed. Position response figures from the experiments are shown in Fig. 10, the red waveform is the positon given signal, and the blue one is the position feedback signal. 

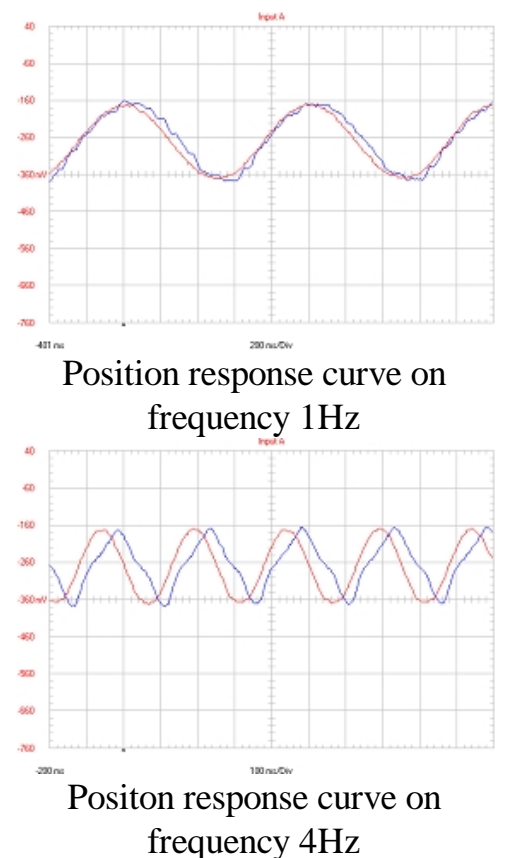
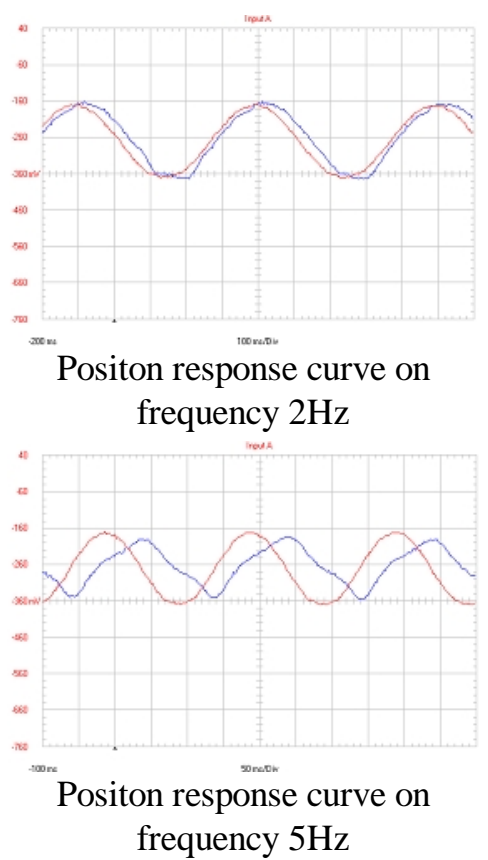
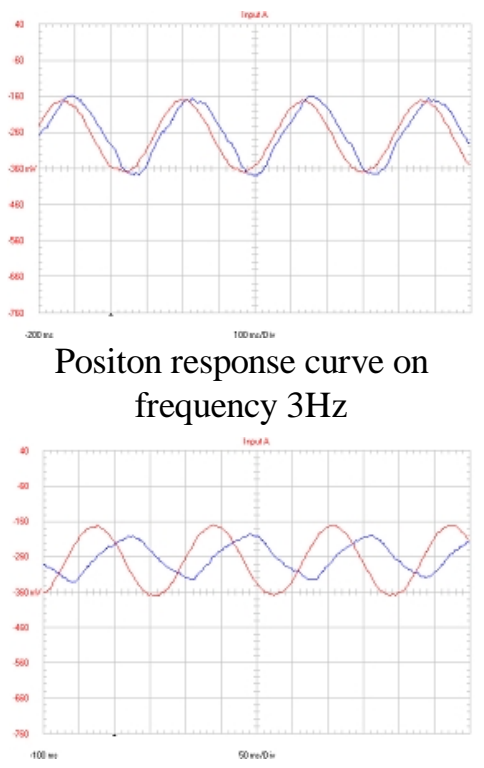

Positon response curve on frequency $6 \mathrm{~Hz}$

Fig.10 the following feature of the prototype position control

It is shown in Fig.10 that the system response characteristic is better at low frequency, however, with the given position signal frequency increasing, the amplitude of the position feedback signal decreases gradually, meanwhile its phase shift increases gradually. Due to the unreliable fixation of the motor output shaft potentiometer and the feedback signal gathering line rotating with the motor shaft, the feedback signal is disturbed, so the feedback signal's sine degree is not good. When the position given signal frequency is $4 \mathrm{~Hz}$, the phase shift is about $45^{\circ}$; when the position given signal frequency is $6 \mathrm{~Hz}$, the amplitude is about $70 \%$ of the given signal one.

\section{Conclusions}

The all-digital EMA AC servo motor designed in this study has large torque, small inertia, high efficiency, compact structure, firmness, easy maintenance and high reliability. The final EMA AC servo system developed from this prototype has a wide transmitted power range, good dynamic performance and small control power, which can satisfy the servo drive needs of tactical missile jet vane and air rudder.

\section{References}

[1] Zhang X, Zhang S, Wang N. A Study on Test Method for Missile Control Actuator System Based on SPHS [J]. Journal of Projectiles Rockets Missiles \& Guidance, 2009, 29(3):77-79.

[2] Zhang J, Yang W, Qi M, et al. Design of Multi-channel Missile Actuator System Based on Nios [J]. Computer Measurement \& Control, 2011, 19(1):81-73.

[3] Liu X, Yunjie W U, Zhang W, et al. Discrete Adaptive Global Sliding Mode Control for Missile Electromechanical Actuator System[J]. Information \& Control, 2013, 42(4):449-456.

[4] Liu X, Wu Y, Deng Y, et al. A global sliding mode controller for missile electromechanical actuator servo system [J]. Proceedings of the Institution of Mechanical Engineers Part G Journal of Aerospace Engineering, 2013, 228(7):1095-1104.

[5]Gao Y. Simulation Research on PID-MRAC Control of Missile Electric-Servo-Actuator [J]. Computer Simulation, 2008.

[6] Hui-Cheng M O. Parameter Analysis on Permanent-Magnet AC Servomotors [J]. Micromotors, 2005. 
[7] Guo H, Yan Z A, Shao-Ping S U. The Research of the Simulation of Permanent-magnet AC Servomotor [J]. Micromotors Servo Technique, 2004. 